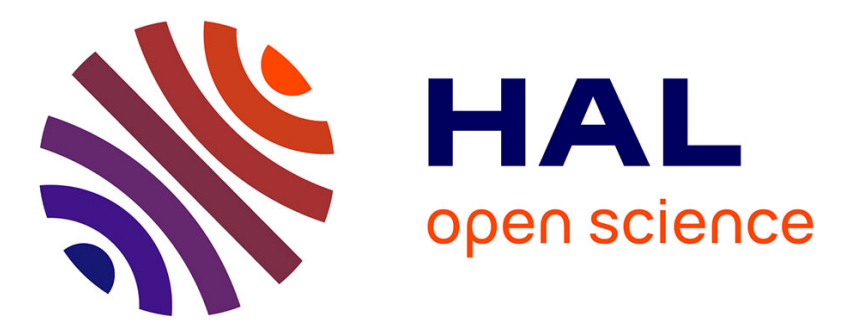

\title{
IRREGULARITIES IN THE YRAST LINE OF 156Er
}

\author{
T. Byrski, F. Beck, C. Gehringer, J. Merdinger, Y. Schutz, J.P. Vivien
}

\section{To cite this version:}

T. Byrski, F. Beck, C. Gehringer, J. Merdinger, Y. Schutz, et al.. IRREGULARITIES IN THE YRAST LINE OF 156Er. International Conference on Nuclear Behaviour at High Angular Momentum, 1980, Strasbourg, France. pp.C10-98-C10-101, 10.1051/jphyscol:19801010 . jpa-00220629

\section{HAL Id: jpa-00220629 https://hal.science/jpa-00220629}

Submitted on 1 Jan 1980

HAL is a multi-disciplinary open access archive for the deposit and dissemination of scientific research documents, whether they are published or not. The documents may come from teaching and research institutions in France or abroad, or from public or private research centers.
L'archive ouverte pluridisciplinaire HAL, est destinée au dépôt et à la diffusion de documents scientifiques de niveau recherche, publiés ou non, émanant des établissements d'enseignement et de recherche français ou étrangers, des laboratoires publics ou privés. 
IRREGULARITIES IN THE YRAST LINE OF ${ }^{156} \mathrm{Er}$

T. Byrski, F.A. Beck, C. Gehringer, J.C. Merdinger, Y. Schutz and J.P. Vivien.

Centre de Recherches Nucléaires et Université Louis Pasteur, F-67037 Strasbourg Cedex, France.

Abstract. - The variation of the moment of inertia vs the rotational frequency has been investigated at high spin values using the ${ }^{141} \operatorname{Pr}\left({ }^{19} \mathrm{~F}, 4 \mathrm{n} \gamma\right){ }^{156} \mathrm{Er}$ reaction. In addition to the backbending at $I=12 \hbar$, a second one has been found at $I=26 \hbar$. Calculations performed by the Warsaw group with the HFB cranking model suggest a probable neutron effect.

As pointed out in several invited talks 1,2$)$ at this Conference, band crossing phenomena have given rise to a large amount of experimental and theoretical work in the last few years. Thus the first backbending near spin value 12 has been extensively studied in the rare earth region and can be understood as a result of weak coupling between two interacting bands, the ground state band crossing generally with an aligned two quasi particle neutron band. Several theoretical calculations have predicted the existence of a second irregularity in the yrast band near spin value 26 , which can be related to rotational alignment, Coriolis antiparing or gapless superconductivity. Experimentally a second anomaly has been observed as an upbending in the yrast line of ${ }^{158}$ Er by the Berkeley group ${ }^{3}$ ), and we have observed another more pronounced one ${ }^{4)}$ in ${ }^{160} \mathrm{Yb}$. The observation of a second discontinuity for these $N=90$ nuclei fits well the picture of an oscillatory behavior of the coupling between the two interacting bands as suggested in Ref. 5 and discussed in one of the invited papers ${ }^{2}$ ) of this Conference.

In the present work our purpose was to search for the existence or non existence of a second backbending with respect to the variation in neu tron number, and for this we have chosen to study the ${ }^{156} \mathrm{Er}$ nucleus.

The decay scheme of the ${ }^{156} \mathrm{Er}$ nucleus had been previously established ${ }^{6)}$ up to $I^{\pi}=24^{+}$; the onset of the first backbending is at $I^{\pi}=12^{+}$. To produce this nucleus, the reactions ${ }^{128} \mathrm{Te}\left({ }^{32} \mathrm{~S}, 4 n\right)^{156} \mathrm{Er}$ and ${ }^{141} \operatorname{Pr}\left({ }^{19} \mathrm{~F}, 4 \mathrm{n}\right){ }^{156} \mathrm{Er}$ have been investigated at severat bombarding energies. We have preferred to use the second one for which the ratio of the $4 n$ channel to the $3 n$ or $5 n$ channel is more pronounced. A fluorine bombarding energy of $95 \mathrm{MeV}$ has been choosen for the experiments. The experimental set-up for the $\gamma-\gamma$ coincidences consisted of an array of three $\mathrm{Ge}(\mathrm{Li})$ detectors located at $+90^{\circ},-90^{\circ}$ and $0^{\circ}$ with respect to the beam direction. This array permits an increase of the counting rate by the simul taneous measurement of three pairs of coincidences and also to measure $D C O$ ratios. These are essential for the determination of the mu1tipole order of the high spin decay transitions since reliable angular distributions are not feasible for these weak $\gamma$-ray lines.

In Fig. 1 are reported the singles spectra 


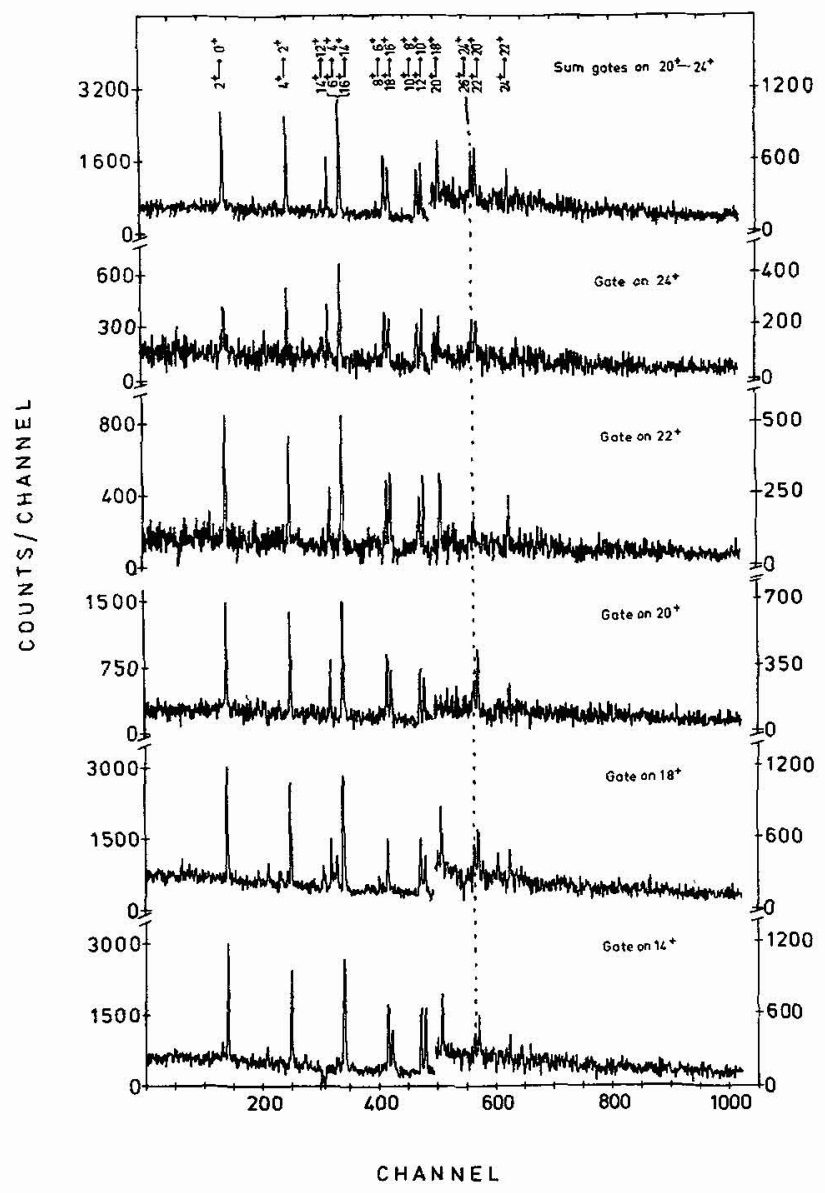

Fig.1: Singles spectra obtained with gates set on $\gamma$-rays issuing from the high-spin states of the yrast band

obtained with gates set on the $\gamma$-rays arising in the decay of the $14^{+}, 18^{+}, 20^{+}, 22^{+}$and $24^{+}$states, as well as a sum spectra with gates set on $\gamma$-rays decaying the $20^{+}, 22^{+}$and $24^{+}$states. The spectrum obtained with the transition decaying the $16^{+}$state has not been reported since this transition has the same energy as the $6^{+}-4^{+}$transition. Beside the $\gamma$-ray lines issuing all from the excited states of the yrast band up to $I^{\pi}=24^{+}$, there appears in each spectrum a line of $766 \mathrm{keV}$ which is different from the $765 \mathrm{keV}$ line known to belong to the odd negative parity band ${ }^{6)}$, since the spectra do not show the presence of any other transition of this band. A 765 keV $\gamma$-ray line could also be populated by the ${ }^{141} \operatorname{Pr}\left({ }^{19} \mathrm{~F}, 3 \mathrm{n}\right){ }^{157} \mathrm{Er}$ reaction or by the radioactivity ${ }^{156} \mathrm{Er} \rightarrow{ }^{156} \mathrm{Ho} \rightarrow{ }^{156}$ Dy but these possi- bilities had to be excluded since the decay transition of the first excited state from these nuclei (266 keV in both cases) is not seen in these spectra. Therefore the $766 \mathrm{keV} \gamma$-ray line is interpreted, on the basis of the relative intensity and the DCO ratios, as the decay of the $I^{\pi}=26^{+}$state of ${ }^{156} \mathrm{Er}$. This would be evidence for the existence of a strong backbending in the yrast band of this nucleus.

In Fig. 2 are shown the spectra obtained in coincidence with the $\gamma$-rays decaying the odd negative parity band. As a confirmation of our assignment, we can see that the decay $\gamma$-rays from the

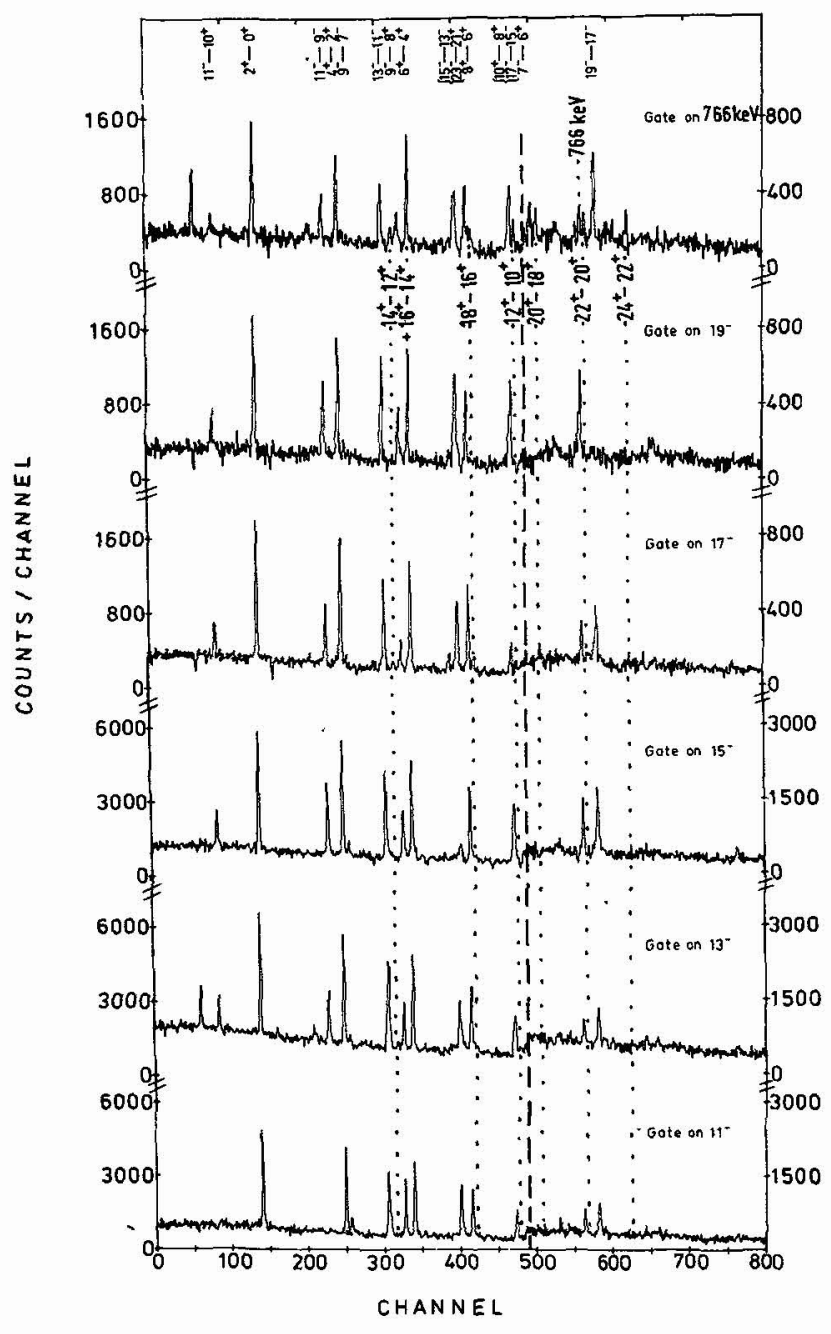

Fig.2 : Singles spectra obtained with gates set as indicated. 
$12^{+}$and higher states appear only in the spectra obtained in coincidence with the $766 \mathrm{keV} \gamma-1 \mathrm{ine}$. In this spectrum we can see some other lines, due to coincidences with the $765 \mathrm{keV}$ transition in ${ }^{157} \mathrm{Er}$, but also a $766 \mathrm{keV} \gamma-1$ ine. Windows placed respectively on the left-hand side (765 keV) and on the righthand side (766 keV) of the gate peak show a feeding pattern of this line similar to the one of the high spin states of the yrast band. Accordingly and also because of the energy and of the relative intensities observed, one can assume the existence of two coincident $766 \mathrm{keV} \gamma$-ray Tines in the yrast band. So a second $766 \mathrm{keV}$ line is tentatively considered as the decay $\gamma$-ray of the $28^{+}$state.

The Warsaw group ${ }^{7)}$ has done the same kind of calculation with the Hartree-Fock-Bogolyubov (HFB) cranking method for ${ }^{156} \mathrm{Er}$ as they have previously successfully done for the interpretation of our experimental results in ${ }^{160} \mathrm{Yb}_{\mathrm{b}}$. Let us first compare the results obtained in ${ }^{160} \mathrm{Yb}$ and ${ }^{156} \mathrm{Er}$ with the HFB cranking method performed at the Strutinsky equilibrium deformation $\left(\beta_{2}=0.23, \beta_{4}=0.02\right)$. Although the first backbending effect appears for both nuclei as the result of a crossing of the two quasi particle neutron band with the ground state band, in contrast to ${ }^{160} \mathrm{Yb}$ case for ${ }^{156} \mathrm{Er}$ the two quasi particle proton band does not cross with the yrast band for this deformation. However a backbending effect due to the crossing between the yrast band and the two quasi proton band can be obtained by lowering the deformation from $\beta_{2}=0.23$ to $\beta_{2}=0.17$. But in this case the backbending would occur at a rotationa, frequency too low as compared to the experimental value, and the values of the moment of inertia thus calculated remain $15-20 \%$ too high. Study of the effect of $\beta_{4}$ (hexadecapole) deformation does not alter calculated results significantly.
Alternative explanations suggested by the HFB calculations performed at the Strutinsky equilibrium deformation are : - A crossing of the yrast band with one of the two 4qp neutron bands which approach the yrast band relatively closely at the backbending spin value

$$
\text { - According to the }
$$

calculations the neutron pairing collapses around $I=24 \hbar$ and the corresponding yrast Tine bends down, producing a cusp in the spin region in which the yrast band and the four quasi particle band would otherwise have crossed.

Beside the experimental decay scheme of the ${ }^{156} \mathrm{Er}$ yrast band reported in Fig.3, we have displayed the variation of the moment of inertia versus the rotational frequency for the higher spin value part of the decay scheme. The calculated moment of inertia at the backbending point correspond to the pairing collapse hypothesis but the general trend

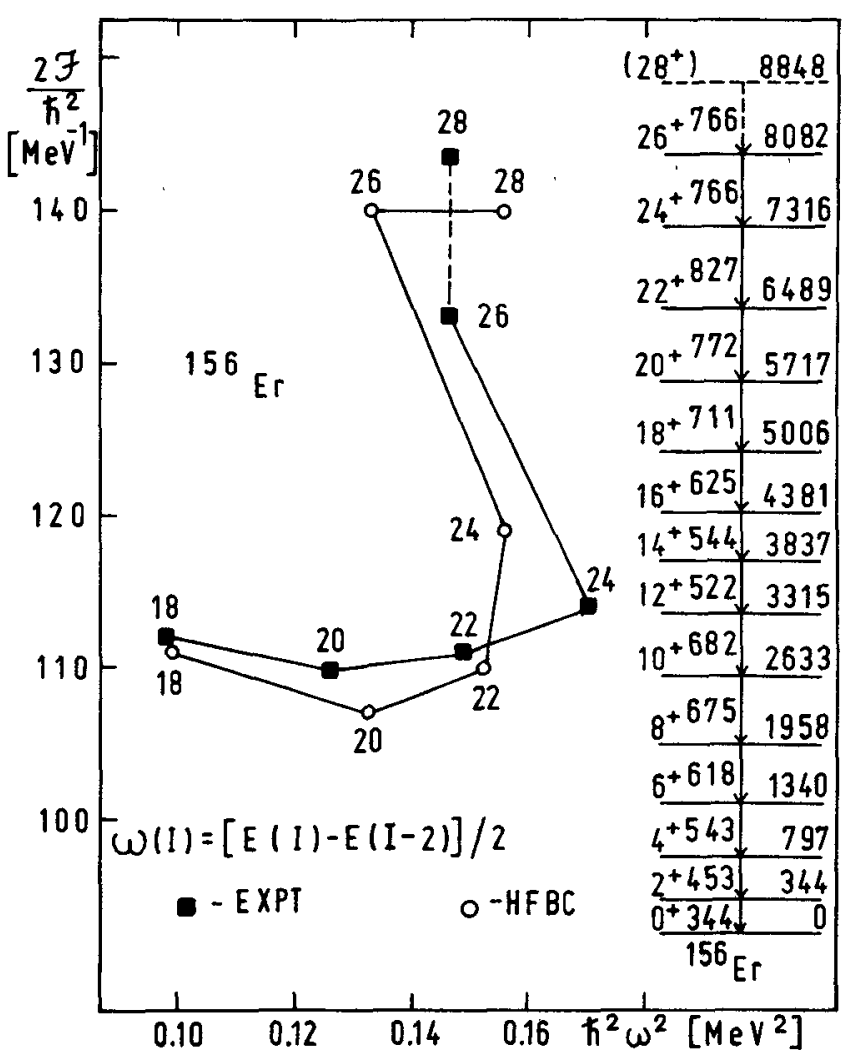

Fig.3. Decay scheme of the yrast band of ${ }^{156} \mathrm{Er}$ and comparison of the HFB calculations with the experimental results for $I^{\pi} \geq 18^{+}$ 
would be very similar if we had considered the case of the crossing of the yrast band with a four quasi neutron band.

In conclusion the second backbending effect observed in ${ }^{156}$ Er can be interpreted as an occu- rance of proton or neutron effects. But the good agreement of the HFB calculations with the experimental results shown in Figure 3 , suggest more likeley a neutron effect.

\section{REFERENCES}

1) R.Bengtsson, Invited talk at this Conference.

2) A.Faessler, Invited talk at this Conference.

3) I.Y.Lee, M.M.Aleonard, M.A.Deleplanque,

Y.El-Masri, J.O.Newton, R.S.Simon, R.M.

Diamond and F.S.Stephens, Phys.Rev.Lett. 38 (1977) 1454 .

4) F.A.Beck, E.Bozek, T.Byrski, C.Gehringer, J.C.Merdinger, Y.Schutz, J.Styczen and J.P. Vivien, Phys.Rev.Lett. 42 (1979) 493.
5) R.Bengtsson, I. Hamamoto and B.R. Mottelson, Phys.Lett. 73B (1978) 259.

6) A.W.Sunyar, E.Der Mateosian, D.C.Kistner, A.Johnson, A.H.Lumpkin and P.Thieberger, Phys.Lett. $62 \mathrm{~B}$ (1976) 283.

7) J.Dudek, W.Nazarewicz and Z.Szymanski, private communication. 